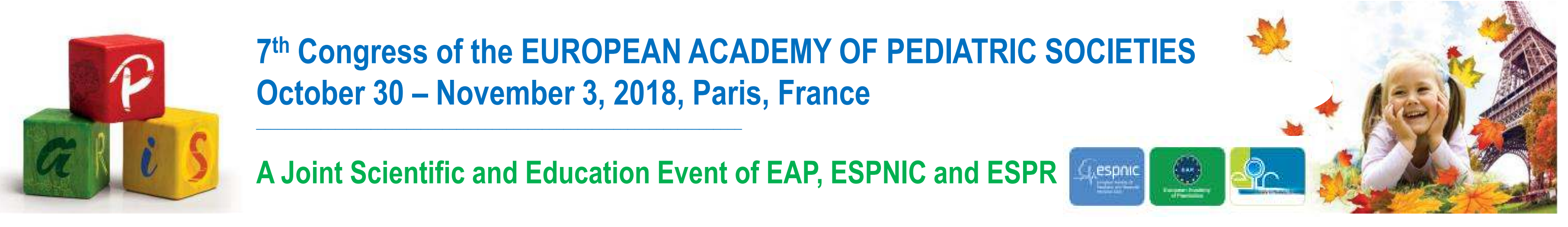

\title{
PHYSICAL DEVELOPMENT OF CHILDREN AND ADOLESCENTS WITH CEREBRAL PALSY
}

Leonid Klimov ${ }^{1}$, Svetlana Dolbnya ${ }^{1}$, Lyudmila Garbuz², Irina Zakharova ${ }^{3}$, Viktoriya Kuryaninova ${ }^{1}$, Marina Stoyan $^{1}$

${ }^{1}$ Stavropol State Medical University, Stavropol, Russia

${ }^{3}$ Russian Medical Academy of Continuing Postgraduate Education, Moscow, Russia

${ }^{2}$ Stavropol Regional Clinical Perinatal Center №1, Department of Pediatrics, Stavropol, Russia

\section{Background and Aims}

Assess the level of physical development of children and adolescents with cerebral palsy (CP), depending on form.

\section{Material and Methods}

102 patients aged from 7 monthы to 17 years for Cerebral Palsy were studied.

Their physical development was assessed with the help of the WHO Anthro/ WHO AnthroPlus programs.

We evaluated the Z-score of height and body mass index with regard for age and sex.

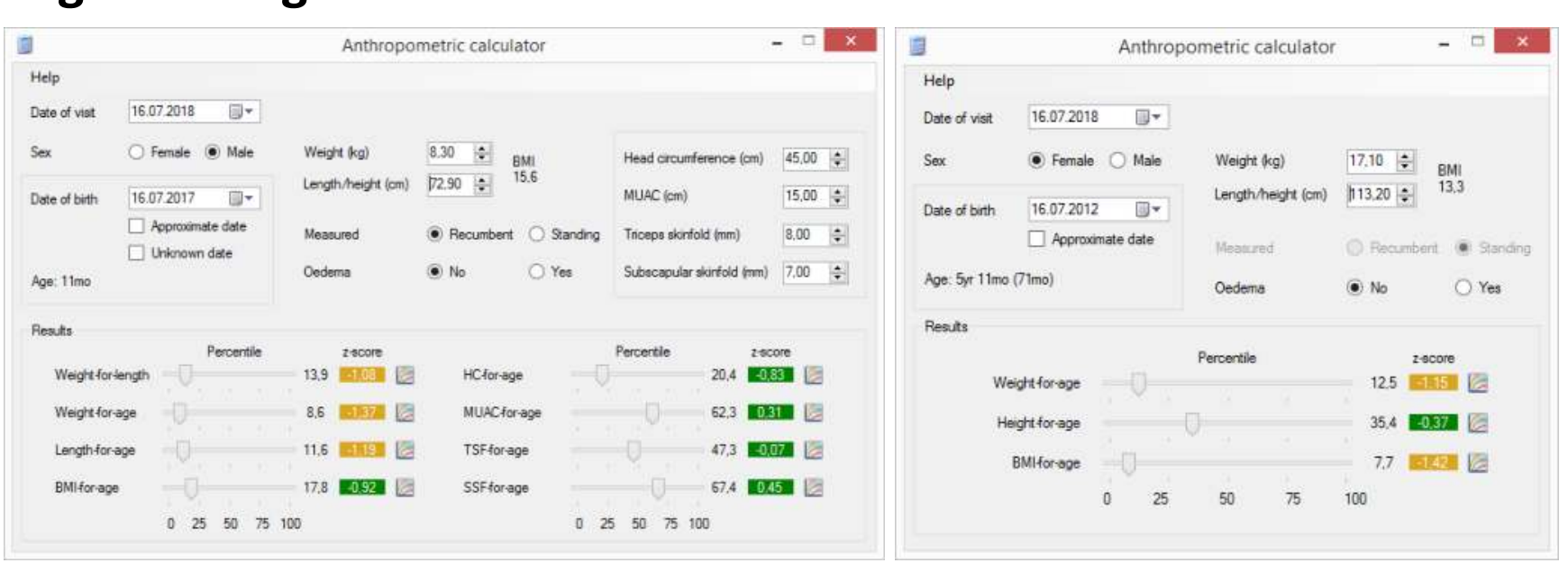

The assessment was carried out in accordance with the WHO standards:

- Overweight BMI for-age > +1SD,

- Obesity BMI for-age > +2SD,

- Thinness BMI for-age <-2SD,

- Severe thinness BMI for-age <-3SD,

- Stunting Height-for-age <-2SD

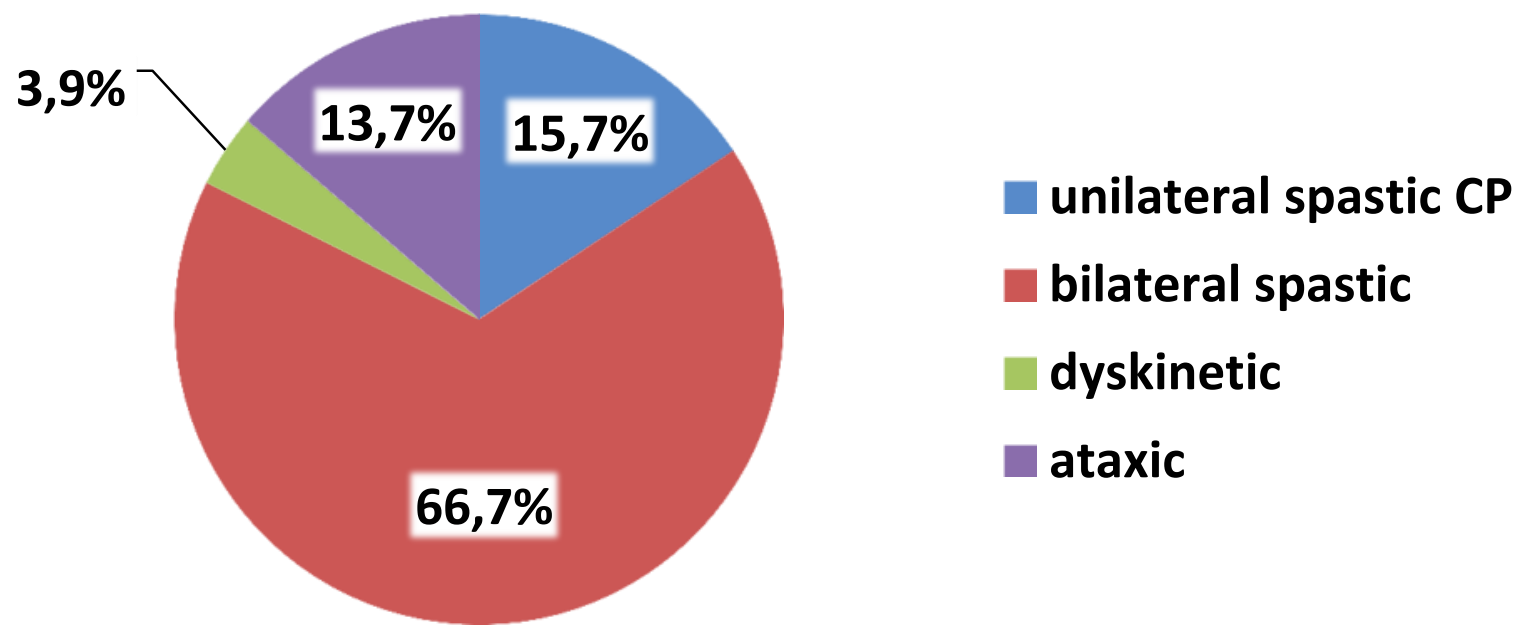

Figure 1. Structure of CP Forms

We used the Surveillance of $\mathrm{CP}$ in Europe classification. 16(15.7\%) patients had unilateral spastic CP, 68(66.7\%) bilateral spastic, 4(3.9\%) dyskinetic, $14(13.7 \%)$ ataxic

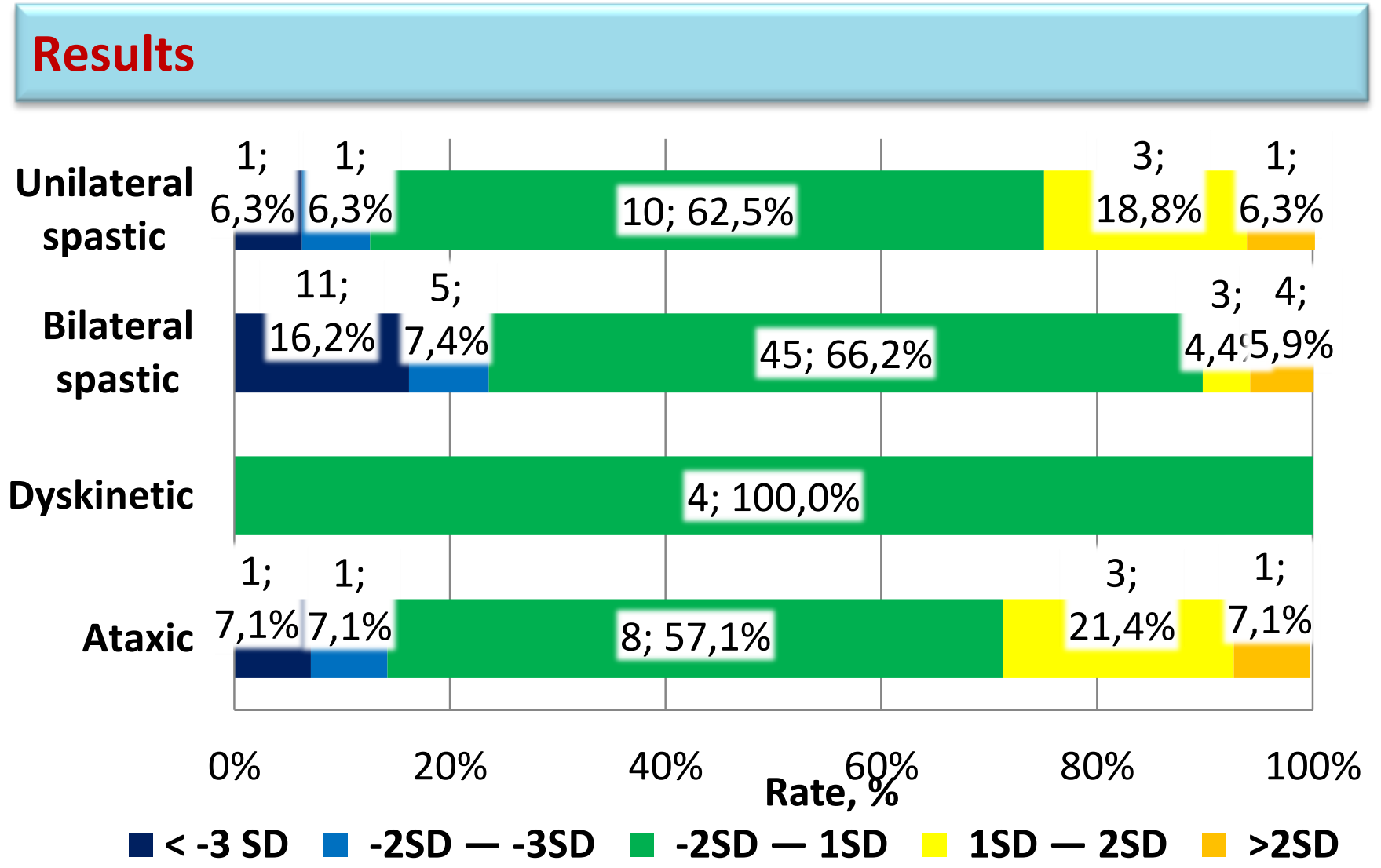

Figure 2. Comparative Analysis of Z-score of Height in Patients with Various CP Forms

Thinness (<-2SD) was found in 20(19.6\%) children with CP, out of whom $13(12.7 \%)$ had demonstrated gross delay in physical development (<-3SD). 9(8.8\%) children were found to be overweight, $6(5.9 \%)$ children were found to be obese.

Thinness (<-2SD) is a little more often demonstrated in bilateral spastic CP patients, while overweight is more often present in patients with unilateral spastic $\mathrm{CP}$ and ataxic $\mathrm{CP}$.

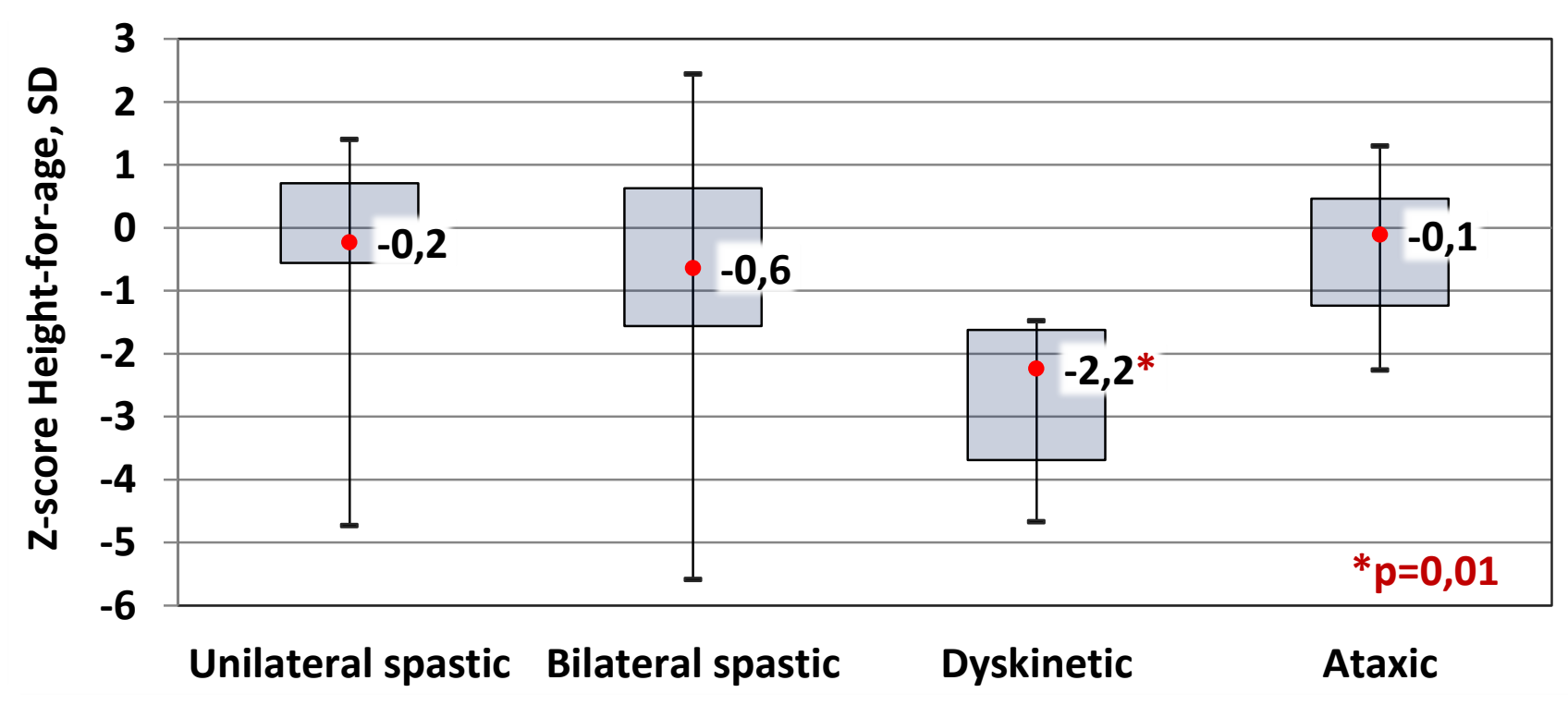

Figure 3. Z-score Height-for-age in Patients with Various CP Forms

Growth delay was found in $12(11.8 \%)$ patients including 2 (12.5\%) patients with unilateral spastic CP, 7 (10.3\%) patients with bilateral spastic CP, $1(7.1 \%)$ patient with ataxic form, 2 (50.0\%) patients with dyskinetic CP ( $p<0.05$ in comparison with other CP forms).

\section{Conclusions}

- Every fifth child or adolescent with CP suffers from body mass insufficiency, 5-8\% of CP patients are overweight and obese.

- Thinness is more often found in patients with bilateral spastic CP, while growth delays are more often observed in patients with dyskinetic $\mathrm{CP}$. 